\title{
Recent Insights into the Management of Behçet Syndrome
}

\author{
Yesim Ozguler (D) \\ Ayse Ozdede \\ Gulen Hatemi $\mathbb{D}$ \\ Istanbul University-Cerrahpasa, \\ Cerrahpasa Medical Faculty, Department \\ of Internal Medicine, Division of \\ Rheumatology and Behçet Disease \\ Research Center, Istanbul, Turkey
}

Correspondence: Gulen Hatemi Istanbul University-Cerrahpasa, Cerrahpasa Medical Faculty, Department of Internal Medicine, Division of Rheumatology and Behçet Disease Research Center, Istanbul, Turkey Tel +902/24l43000/21793

Email gulenhatemi@yahoo.com

\begin{abstract}
Behçet syndrome (BS) is a multisystem vasculitis with variable vessel involvement that shows significant heterogeneity among patients in terms of clinical manifestations and disease course. Treatment choice and response are both influenced by this heterogeneity. BS treatments' main goals are to quickly suppress inflammatory exacerbations and prevent relapses in order to protect organ functions and provide good quality of life. Besides the long-term experience with steroids and traditional immunosuppressives, biologic drugs, especially TNF inhibitors, have gained increasing importance in the treatment of BS over the years. In this review, we aimed to give an overview of the studies with conventional and biological drugs with proven efficacy in the treatment of BS, as well as promising drugs and current management strategies according to clinical phenotypes.
\end{abstract}

Keywords: Behçet syndrome, treatment, management, biologic agents, TNF inhibitor

\section{Introduction}

Behçet syndrome (BS) is a relapsing, multisystem inflammatory vasculitis characterized by oral (OU) and genital ulcers (GU), as well as involvement of the joints, ocular, vascular, nervous, and gastrointestinal systems. For many years, BS was thought to be an autoimmune disease. However, there are certain clinically significant differences between BS and other autoimmune diseases, such as sex differences in disease manifestations, lack of autoantibodies, and comorbidities (eg, premature atherosclerosis). ${ }^{1,2}$ In recent years, BS has begun to be considered as an autoinflammatory disease. Just as in autoimmune diseases, there are some differences between BS and autoinflammatory diseases. Autoinflammatory disorders are typically seen in children with recurrent fever syndromes; however, BS is quite rare in the pediatric age group, and recurrent fever is not a part of the BS clinical feature. ${ }^{1}$ Also, vasculitis is an important feature of BS, which is not the case in autoinflammatory diseases. Moreover, IL1 inhibition, which has been shown to be effective in the treatment of autoinflammatory illnesses, has only a limited effect on some subgroups of BS patients.

The basic principles in BS treatment are to suppress inflammation promptly and prevent damage and relapses. Since the disease has a heterogeneous nature, its treatment varies according to the type of involvement. Mucocutaneous and joint involvement in BS patients may reduce the quality of life (QoL) but do not result in permanent damage. Conventional treatment is the first choice in these patients. On the other hand, immunosuppressive treatment is mandatory in patients with major organ involvement. Otherwise, it can cause morbidity or mortality. Male gender and young age are other important prognostic factors and affect the choice of treatment. 
In this review, we aimed to give an overview of the studies with conventional and biological drugs with proven efficacy in the treatment of BS, as well as promising drugs and current management strategies according to clinical phenotypes. For this purpose, studies retrieved during the systematic reviews for the 2018 update of the EULAR recommendations for the management of BS, as well as more recent studies that were published since then were reviewed. ${ }^{3-5}$

\section{Conventional Treatment Modalities} Colchicine

The efficacy of colchicine was evaluated in 3 different randomized controlled trials (RCT) with different conclusions (Table 1). In the first RCT ( $\mathrm{n}=28)$, no beneficial effect of colchicine was found in BS patients with mucocutaneous and ocular involvement during 6 months. ${ }^{6}$ On the other hand, the authors reported that colchicine might still have some efficacy

Table I The Effect of Drugs According to the Types of Involvement in Behçet Syndrome

\begin{tabular}{|c|c|c|c|c|c|c|c|}
\hline \multirow[t]{2}{*}{ Drugs } & \multirow{2}{*}{$\begin{array}{l}\text { Type of } \\
\text { Study }\end{array}$} & \multicolumn{6}{|c|}{ Type of Organ Involvement } \\
\hline & & $\begin{array}{c}\text { Skin and } \\
\text { Mucosa }\end{array}$ & Joint & Uveitis & $\begin{array}{c}\text { Vascular } \\
\text { Involvement }\end{array}$ & $\begin{array}{c}\text { CNS } \\
\text { Involvement }\end{array}$ & $\begin{array}{c}\text { GI } \\
\text { Involvement }\end{array}$ \\
\hline \multirow[t]{2}{*}{ Colchicine } & RCT & $\checkmark$ & $\checkmark$ & $x$ & & & \\
\hline & OS & & & & & & \\
\hline \multirow[t]{2}{*}{ Apremilast } & RCT & $\checkmark$ & & & & & \\
\hline & OS & $\checkmark$ & (3) & & & & \\
\hline \multirow[t]{2}{*}{ Azathioprine } & RCT & $\checkmark$ & $\checkmark$ & $\checkmark$ & & & \\
\hline & OS & & & $\checkmark$ & $\checkmark$ & $\checkmark$ & $\checkmark$ \\
\hline \multirow[t]{2}{*}{ Cyclosporine-A } & RCT & & & $\checkmark$ & & & \\
\hline & OS & & & & $\checkmark$ & $\Delta$ & \\
\hline Cyclophosphamide & OS & & & (ㄱ) & $\checkmark$ & (త) & \\
\hline \multirow[t]{2}{*}{ Interferon-alpha } & RCT & $\checkmark$ & $x$ & $\checkmark$ & & & \\
\hline & OS & $\checkmark$ & $\checkmark$ & $\checkmark$ & $\checkmark$ & (3) & \\
\hline \multirow[t]{2}{*}{ TNF-inhibitors } & RCT & $\checkmark$ & $\checkmark$ & & & & \\
\hline & OS & $\checkmark$ & $\checkmark$ & $\checkmark$ & $\checkmark$ & $\checkmark$ & $\checkmark$ \\
\hline \multirow[t]{2}{*}{ IL-I inhibitors } & RCT & & & $x$ & & & \\
\hline & OS & $\checkmark$ & $\checkmark$ & $\checkmark$ & & & \\
\hline IL-6 inhibitors & OS & $\Delta$ & $\Delta$ & $\checkmark$ & $\checkmark$ & $\checkmark$ & \\
\hline \multirow[t]{2}{*}{ IL-I7 inhibitors } & RCT & & & $x$ & & & \\
\hline & OS & (3) & $\checkmark$ & & & & \\
\hline IL-23 inhibitors & OS & $\checkmark$ & & & & & \\
\hline \multirow[t]{2}{*}{ Thalidomide } & RCT & $\checkmark$ & $x$ & & & & \\
\hline & OS & & & & & & $\checkmark$ \\
\hline Mycophenolic acid & OS & (3) & & $\checkmark$ & $\checkmark$ & $\checkmark$ & \\
\hline Tofacitinib & OS & & $\checkmark$ & $\checkmark$ & $\checkmark$ & & \\
\hline
\end{tabular}

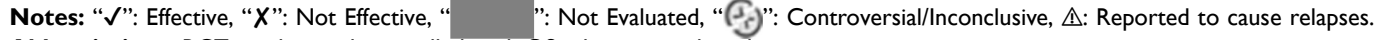

Abbreviations: RCT, randomized controlled trial; OS, observational study. 
on erythema nodosum (EN) and arthralgia. In the second and larger RCT $(n=116)$ led by the same group, colchicine was found effective on EN and GUs in women and arthritis in both genders during 2 years. ${ }^{7}$ On the other hand, the third RCT $(n=169)$ reported significant improvement in OUs, pseudofolliculitis, as well as GUs and EN during the 4-months trial. $^{8}$ In all 3 trials colchicine was generally well tolerated and did not cause any serious adverse effects (AEs).

Long-term prognosis of patients who took part in the second RCT were evaluated after about 17 years. ${ }^{9}$ Among 90 (78\%) patients who could be contacted, 28 (31\%) had to receive immunosuppressives during the posttrial period. Fourteen of these patients were on colchicine arm and continuous use of colchicine did not decrease the use of immunosuppressives in the long-term.

\section{Azathioprine}

There is only one RCT for azathioprine $(2.5 \mathrm{mg} / \mathrm{kg} /$ day $)$ in BS (Table 1). It was a 24 month, double-blind, placebocontrolled trial including 73 male patients. ${ }^{10}$ There were 2 groups. The first group included BS patients without uveitis, while the second included BS patients with uveitis. Azathioprine was found effective in the prevention of new eye involvement (RR 0.14, 95\% CI 0.02-0.93) and decreasing the episodes of hypopyon uveitis (RR 0.06 , 95\% CI 0.01-0.43). Extraocular manifestations were also evaluated and it was observed that OUs, GUs and arthritis were less in the azathioprine group than in the placebo group. No significant AEs were reported in the azathioprine group.

After the trial, the long-term effect of azathioprine on BS prognosis was evaluated. ${ }^{11}$ Sixty-two (85\%) patients had a follow-up data for a mean $94 \pm 10$ months. In group 2 , the blindness rate after the trial ended was $40 \%$ in the placebo arm while it was $13 \%$ in azathioprine arm. The number of patients who required immunosuppressives such as azathioprine, cyclosporine-A or cyclophosphamide after the trial was also substantially higher in the placebo group than in the azathioprine group (61\% vs 32\%). On the other hand, the total duration of immunosuppressive treatment was similar in the two groups at the time of reevaluation. A 2-line reduction in visual acuity occurred in 6 of 10 placebo patients compared to 3 of 10 AZA patients who entered the study within 2 years of the onset of eye involvement. This happened in 2 of 7 placebo patients compared to 1 of 9 AZA patients who had entered the original trial with a duration of eye involvement of $>2$ years. This result suggests that the early initiation of azathioprine may cause a favorable outcome on the longterm prognosis of BS.

Two retrospective studies reported the efficacy of azathioprine in the treatment of gastrointestinal involvement. The first study reported that clinical and endoscopic remission was achieved in $24(65 \%)$ of $37 \mathrm{BS}$ patients with active moderate or severe gastrointestinal involvement after a mean follow-up of $68.6 \pm 43.6$ months. ${ }^{12}$ Sixteen patients with mild gastrointestinal involvement were treated with 5-ASA in the same study. Ten $(63 \%)$ of these patients achieved complete remission (CR) without relapse during a mean follow-up of $89.3 \pm 64.5$ months. Refractory or relapsing patients were treated with azathioprine. The second study included $67 \mathrm{BS}$ patients who were treated with azathioprine as a first line agent for gastrointestinal involvement. $^{13}$ Thirty-nine of the 67 patients $(58.2 \%)$ received azathioprine for maintenance of clinical remission. They reported that the cumulative relapse rates were $5.8 \%, 28.7 \%, 43.7 \%$ and $51.7 \%$ at 1,2 , 3 and 5 years, respectively.

Although azathioprine was the most frequently preferred conventional DMARD in vascular involvement in retrospective studies, still there is no study directly showing its efficacy. In our prospective observational study, among 29 patients treated with azathioprine with a mean follow-up of $20.2 \pm 15.8$ months, 13 (45\%) had relapses. ${ }^{14}$ In a recent study, two different azathioprine doses (Group$\mathrm{A} \geq 2 \mathrm{mg} / \mathrm{kg} / \mathrm{d}, \mathrm{n}=59$ vs Group-B $<2 \mathrm{mg} / \mathrm{kg} / \mathrm{d}, \mathrm{n}=19$ ) were compared for prevention of relapse of venous involvement as maintenance therapy. ${ }^{15}$ Relapse rate was lower (14\% vs $32 \%$ ) and mean duration of relapse free time was longer $(111.6 \pm 11.2$ vs $51.5 \pm 6.1$ months $)$ in group-A compared to group-B.

In a retrospective study, azathioprine plus corticosteroid was compared to cyclophosphamide plus corticosteroid in patients with severe parenchymal involvement. ${ }^{16}$ Although relapse rate seemed less in patients using cyclophosphamide, this difference disappeared in the 5 th, 7 th, and 10th years.

Azathioprine is generally well tolerated and may cause transient transaminase elevation and cytopenia, especially in thiopurine methyl transferase deficiency. Caution is required when using azathioprine in combination with other drugs. An open study using interferon-alpha and azathioprine together was terminated prematurely due to myelosuppression. ${ }^{17}$ Concomitant use with warfarin may also be problematic, decreasing the efficacy of warfarin. 


\section{Cyclosporine-A}

The efficacy of cyclosporine-A in BS uveitis was evaluated in 3 RCTs with 3 different comparators (chlorambucil, colchicine, cyclophosphamide) (Table 1). ${ }^{18-20}$ Cyclosporine-A was found effective in decreasing the frequency (RR 2.47, 95\% CI 1.68-3.64) and severity of ocular attacks (RR 2.11, 95\% CI 1.44-3.10) and improving visual acuity (MD 3.0, 95\% CI 0.6-5.4). Only 1 RCT reported renal dysfunction and hirsutism as cyclosporineA-related AEs. On the other hand, nephrotoxicity, hypertension, and hirsutism were reported as the most common AEs in several cyclosporine-A open-label studies. ${ }^{4}$

Cyclosporine-A is frequently used in combination with azathioprine in patients with eye involvement. Although there is no comparative data showing the superiority of this combination to either drug alone, adding cyclosporineA to treatment in patients who have uveitis relapses during azathioprine has provided some benefit. ${ }^{21}$

There are 4 studies assessing the risk of nervous system involvement in BS patients using cyclosporineA. A meta-analysis of these studies showed that the use of cyclosporine-A is associated with an increased risk of nervous system involvement (RR 8.26, 95\% CI 4.45$15.32)^{4}$

\section{Mycophenolic Acid}

The efficacy of mycophenolic acid derivatives in mucocutaneous involvement was evaluated in 2 prospective studies, and different results were obtained (Table 1). A prospective study conducted with mycophenolate mofetil (MMF, 2-3 g/day) was planned to evaluate its efficacy for six months in $30 \mathrm{BS}$ patients with mucocutaneous involvement. ${ }^{22}$ However, the study was terminated early due to the inefficacy of MMF in the first six patients. In the second study conducted with enteric-coated mycophenolate sodium (MPS) (720 mg bid), 10 BS patients with mucocutaneous involvement refractory to previous treatment (eg, colchicine, azathioprine, and systemic steroids) were evaluated for 6 months. ${ }^{23}$ The activity of mucocutaneous involvement significantly decreased in 8 patients in the first two months, and two other patients showed improvement at four months. No significant $\mathrm{AE}$ requiring withdrawal of MPS was observed.

The efficacy of MMF was evaluated in 39 BS patients with different types of organ involvement (vascular $=26$, uveitis $=11$, and neuro-BS=2) in a retrospective study. ${ }^{24}$ Thirty-one patients received MMF for maintenance of remission, and 8 received for induction of remission. After a mean follow-up of $18 \pm 13$ months, 33 (85\%) patients were still on MMF treatment. MMF was discontinued only in 3 patients due to disease activity.

The beneficial effect of MMF in 4 patients with parenchymal neuro-BS was also reported in a case series. ${ }^{25}$

\section{Cyclophosphamide}

In 2 small retrospective studies, cyclophosphamide was compared to other treatments (surgery or azathioprine and corticosteroids) to evaluate the mortality rates in BS patients with pulmonary artery (PA) involvement (Table 1). In the first study, 6 of the 17 patients in the CYC group died, while all 5 patients in the comparison group died (RR 0.35, 95\% CI 0.19-0.67). ${ }^{26}$ The second study also showed a similar mortality rate $(1 / 4 \mathrm{vs} 5 / 5){ }^{27}$

In a retrospective study, the use of cyclophosphamide $(n=31)$ in patients with severe parenchymal neuro BS patients had a tendency towards a higher event-free survival rate at first year compared to azathioprine use $(\mathrm{n}=12)$ (RR 0.62, 95\% CI 0.38-1.01). ${ }^{16}$ However, this difference was not observed at the 5th, 7 th, and 10th years. In another retrospective study, combination therapy of cyclophosphamide and corticosteroid $(\mathrm{n}=7)$ did not provide beneficial effects for preventing relapses compared to corticosteroid alone $(n=14){ }^{28}$

In a recent retrospective study, the long-term outcome and AEs in 198 BS patients ( $93 \%$ men) who had received cyclophosphamide between 1976 and 2006 were evaluated $^{29}$ Main indications for cyclophosphamide use were vascular (67\%) and ocular $(27 \%)$ involvement. The median duration of cyclophosphamide use was 12 months and the cumulative dose was $13.5 \mathrm{~g}$. Short term AEs such as hemorrhagic cystitis $(n=7)$ and infection $(n=4)$ were observed in $17(9 \%)$ patients. After a median follow-up of 25 years $15(8 \%)$ patients had malignancy and $26(30 \%)$ patients had infertility. Among 52 (26\%) patients who died, the main reasons for death were vascular complications of BS in $27(52 \%)$, malignancy in $7(13 \%)$, and infection in $5(10 \%)$ patients.

\section{Thalidomide}

The efficacy of thalidomide in mucocutaneous involvement was evaluated in a 24 -week RCT (Table 1). ${ }^{30}$ Ninetysix male patients with mucocutaneous involvement were included and two different doses (100 mg/day and $300 \mathrm{mg} /$ day) of thalidomide were tested. Both doses were shown to be effective in achieving CR of OUs and GUs during 24 
weeks at visits (RR 21, 95\% CI 1.28-343 for $100 \mathrm{mg}$ and RR 19.6, 95\% CI 1.19-322 for $300 \mathrm{mg}$ ). Thalidomide did not show any beneficial effect on arthritis, and the number of nodular lesions increased in the first 2 months of treatment. However, the authors reported that these lesions could be superficial thrombophlebitis, which is very difficult to differentiate from EN clinically. Thalidomide was discontinued due to severe sedation in 3 patients and polyneuropathy in 1 patient. Polyneuropathy developed in 3 more patients after the trial ended.

The efficacy of thalidomide on refractory gastrointestinal involvement of BS was reported in a case series and systematic review (SR). A total of 19 patients were treated with thalidomide and clinical remission was obtained in 16 (84\%) patients. $^{31}$

\section{Biologic Agents Interferon-Alpha}

Interferon-alpha was studied in 2 RCTs and several openlabel and retrospective studies (Table 1). The first RCT, which included 44 patients, showed a significant reduction in the duration and pain of OUs, as well as the frequency of GUs and papulopustular lesions during 3 months of treatment. ${ }^{32}$ However, the $\mathrm{CR}$ rate was not different between the placebo and interferon-alpha groups. The second RCT was a head-to-head study comparing interferon-alpha and cyclosporine-A. ${ }^{33}$ However, it was terminated prematurely since the targeted number of patients could not be reached. On the other hand, in the analysis of 13 patients on each arm, interferon-alpha was found superior to cyclosporine-A in ocular remission, visual acuity, and posterior uveitis score.

There is still no head-to-head study comparing interferon-alpha with TNF inhibitors (TNFis) in BS treatment. A pooled analysis of retrospective and open-label studies with these two drugs was performed in a SR. ${ }^{4} \mathrm{CR}$ rates of both agents were similar (64\% for interferon-alpha vs $57 \%$ for infliximab). Sustained remission rate ( $71 \%$ vs $44 \%$ ) and corticosteroid cessation rate $(66 \%$ vs $33 \%)$ were higher with interferon-alpha, while improvement in visual acuity ( $46 \%$ vs $76 \%$ ) was higher with infliximab.

Interferon-alpha was found effective in the treatment of arthritis in 4 observational studies. Three of them reported $\mathrm{CR}$ in all patients $(\mathrm{n}=43)$, and the other reported significant reduction in the mean duration and the frequency of arthritis. ${ }^{4}$
In an open study, CR of vascular involvement was achieved in 9 out of 10 patients with interferon-alpha. A similar result was observed in a prospective study. ${ }^{14}$ Although it was not a head-to-head study, a lower relapse rate $(12 \%$ vs $45 \%)$ and higher recanalization rate $(86 \%$ vs $45 \%)$ was observed with interferon-alpha compared to azathioprine.

In a single masked RCT, pegylated interferon-alpha in addition to standard of care therapy was compared to standard of care therapy alone. ${ }^{34}$ However, the study did not meet the primary outcome, which was defined as decreasing prednisolone dose requirement to $10 \mathrm{mg}$ or less at month 12 .

Flu-like symptoms were the most commonly reported AEs in interferon-alpha studies. Depression, leucopenia, thrombocytopenia, alopecia, and transaminase elevation were other AEs. ${ }^{4}$

\section{TNF Inhibitors}

There is increasing data on TNFis in the treatment of BS. Only etanercept was evaluated in a 4-week RCT (Table 1) OUs $(9 / 20$ vs $1 / 20)$ and EN (17/20 vs 5/20) were found significantly lower in the etanercept group compared to placebo. ${ }^{35}$ No difference on GUs was observed between 2 groups. The efficacy of etanercept on GUs may have been underestimated due to small sample size and the short duration of the study. There are also 2 RCTs showing that adalimumab is effective in non-infectious uveitis. ${ }^{36,37}$ However, the number of BS patients was low and no subgroup analysis according to diseases was performed in these trials.

Recently, a SR and meta-analysis evaluating the efficacy of infliximab and adalimumab in BS uveitis was published. ${ }^{38}$ They included articles published between January 2010 and September 2019 with a minimum of 10 patients and a minimum of 6 months of follow-up. Eighteen studies with a total of 968 patients $(\mathrm{M} / \mathrm{F}=65 \%$ / $35 \%$ ) were included. Infliximab was evaluated in 10, adalimumab in 4 and both agents in 4 studies. Although the meta-analysis has high heterogeneity, TNFis were found effective in achieving remission (68\%), improving visual acuity $(60 \%)$, decreasing central macular thickness, and cessation of corticosteroid (38\%).

There are two studies comparing the efficacy of infliximab and adalimumab in uveitis (Table 2). An open-label, multicenter study from Spain reported the comparison of infliximab $(n=103)$ and adalimumab $(n=74)$ in 177 BS 
Table 2 Comparisons of Infliximab and Adalimumab in the Treatment of Behçet Uveitis in Retrospective Studies

\begin{tabular}{|c|c|c|c|c|}
\hline & \multicolumn{2}{|c|}{$\begin{array}{c}\text { Atienza-Mateo B. et al, } 2019 \\
\text { I } 77(94 \mathrm{M} / 83 \mathrm{~F})\end{array}$} & \multicolumn{2}{|c|}{$\begin{array}{l}\text { Fabiani C. et al, } 2019 \\
\qquad 107 \text { (6I M/46 F) }\end{array}$} \\
\hline & IFX & ADA & IFX & ADA \\
\hline$n$ of patients & $103(55 \mathrm{M} / 48 \mathrm{~F})$ & $74(39 \mathrm{M} / 35 \mathrm{~F})$ & 41 & 66 \\
\hline$n$ of eyes & 185 & $13 \mid$ & 73 & 114 \\
\hline Mean age (SD) & $40.4(10.1)$ & $38.7(11.3)$ & $42.2(12.1)$ & $39.5(12.1)$ \\
\hline Duration of uveitis ${ }^{a}$ & $36[12-72]$ & $24[12-60]$ & II.6 (8.6) & 9.1 (7.4) \\
\hline \multicolumn{5}{|l|}{ Pattern of uveitis (\%) } \\
\hline Posterior & $28(27.2)$ & $14(18.9)$ & $22(52.4)$ & $24(36.4)$ \\
\hline Panuveitis & $64(62.1)$ & $45(60.8)$ & $19(45.3)$ & $37(56.1)$ \\
\hline Intermediate & $0(0)$ & I (I.4) & I (2.4) & $5(7.6)$ \\
\hline Retinal vasculitis ${ }^{b}$ & $114(61.6)$ & $78(59.5)$ & $25(61.0)$ & $46(69.7)$ \\
\hline \multicolumn{5}{|l|}{ Previous treatment (\%) } \\
\hline Corticosteroid & 95 & 88 & 100 & 100 \\
\hline Cyclosporine & 75 & 78 & 23 & 27 \\
\hline Azathioprine & $57^{c}$ & $42^{c}$ & 8 & 17 \\
\hline Methotraxate & 44 & 42 & 12 & 20 \\
\hline Combination with cDMARD \% & 76.5 & 70.3 & 48.8 & 46.7 \\
\hline Cyclosporine & $4 I .1$ & 55.7 & 40 & 22.6 \\
\hline Azathioprine & 21.8 & 19.2 & 15 & 29 \\
\hline Methotraxate & 33.3 & 21.1 & 30 & 35.4 \\
\hline MMF & 1.3 & 3.8 & 20 & 3.2 \\
\hline Mean follow-up TNFis (mo) & $31.5 \pm 23.5$ & $26.5 \pm 18.6$ & $56.6 \pm 56.0$ & $26.5 \pm 21.7$ \\
\hline \multicolumn{5}{|l|}{ Treatment outcomes at mo 12} \\
\hline Improvement of $\mathrm{ACl} \%$ & 78.2 & 92.3 & NA & NA \\
\hline Improvement of vitritis \% & $79.0^{\mathrm{d}}$ & $93.3^{d}$ & NA & NA \\
\hline Improvement of RV \% & 97 & 95 & 86.3 & 71.4 \\
\hline Macular thickness & $264.9 \pm 59.7$ & $250.6 \pm 36.9$ & $\mathrm{NA}^{\mathrm{e}}$ & $N A^{e}$ \\
\hline BCVA & $0.67 \pm 0.34^{f}$ & $0.8 I \pm 0.26^{\mathrm{f}}$ & $0.4 \pm 0.0$ & $0.4 \pm 0.11$ \\
\hline Decrease of uveitis attack\% & NA & NA & 84.2 & 66.7 \\
\hline Drug retention rate \% & $85.0^{g}$ & $95.2^{\mathrm{g}}$ & 87.8 & 79.8 \\
\hline Severe $A E /$ toxicity & $8(7.8)$ & $4(3.9)$ & NA & NA \\
\hline
\end{tabular}

Notes: ${ }^{c} p=0.049,{ }^{d} p=0.04,{ }^{f} p=0.001,{ }^{g} p=0.042$. ${ }^{a}$ Disease duration given as median $[I Q R]$ in the first study and mean (SD) in the second study. ${ }^{b}$ Retinal vasculitis was reported the number of involved eye in the first study and the number of patient in the second study. ${ }^{e}$ No quantitative measurements for macular thickness was given in the second study. However, central macular thickness was significantly lower in infliximab group compared to adalimumab group at the last follow-up.

Abbreviations: ADA: adalimumab, AE: adverse event, IFX: infliximab; $\mathrm{ACl}$, anterior chamber inflammation; RV, retinal vasculitis; $\mathrm{BCVA}$, Best corrected visual acuity; MMF, mycophenolate mofetil; NA, not available.

patients with uveitis refractory to classical immunosuppressives. ${ }^{39}$ All ocular parameters improved in both groups after one year of treatment. On the other hand, significantly better results were obtained with adalimumab in vitritis (79\% vs 93\%), best-corrected visual acuity and drug retention rate ( $85 \%$ vs $95 \%)$. Seventy-eight patients $(77 \%)$ in the infliximab group and $52(70 \%)$ in the adalimumab group continued with conventional immunosuppressives during a 1-year period. Prednisone reduction rate was similar in both groups. A multicenter study from Italy compared the efficacy of adalimumab and infliximab in 107 patients with non-infectious uveitis, of whom 74 had BS uveitis. $^{40}$ Sixty-six (62\%) patients were treated with adalimumab and $41(38 \%)$ with infliximab. Both drugs were effective in decreasing ocular attacks. The percentage of patients using corticosteroid and the frequency of macular edema at month 12 and at the last visit were significantly higher in adalimumab group compared to infliximab group. 
The long-term efficacy and safety of adalimumab in 462 BS patients with gastrointestinal involvement has recently been published. ${ }^{41}$ The efficacy of adalimumab was evaluated in 383 patients and reported as "markedly effective", "effective", or "ineffective" at the last observation time point according to physician's discretion. Adalimumab was "effective" in $41 \%$ and "markedly effective" in $44 \%$ of patients. The safety of adalimumab was evaluated in 462 patients. AEs and serious AEs were reported in $26 \%$ and $11 \%$ patients, respectively. The most common $\mathrm{AE}$ was infection $(n=47)$ which was followed by injection site reaction $(n=5)$, and tuberculosis $(\mathrm{n}=3)$.

Two other TNFis, certolizumab and golimumab, were also studied in BS. In the first study, certolizumab was used for different indications (joint $=8$, mucocutaneous $=6$, eye $=4$, gut $=4$, nervous $=2$ ) in 13 BS patients with a mean disease duration of $8.80 \pm 6.9$ years. $^{42}$ Only two of those patients received certolizumab as a first-line biologic therapy. Six patients $(46 \%)$ experienced a worsening of the symptoms after $4.16 \pm 1.21$ months of certolizumab while seven $(54 \%)$ were still receiving certolizumab at the last follow-up visit, after $9.28 \pm 3.03$ months of treatment. In the second study, the efficacy of golimumab was evaluated in 17 BS patients. ${ }^{43}$ None of those patients received golimumab as a first-line biologic treatment. Indications were joint involvement in 14, mucocutaneous involvement in 7 , gastrointestinal involvement in 6 and eye involvement in 3 patients. BS manifestations resolved in 16/17 (94.1\%) patients at the third month of golimumab. Significant decrease in disease activity was observed and it was higher in patients co-administered with DMARDs than those receiving golimumab as monotherapy.

The efficacy of TNFis was evaluated in a total of 141 patients with mostly severe or refractory vascular involvement (venous and/or arterial) in 9 retrospective studies. ${ }^{44,45}$ Remission data was available for 126 patients, of which 121 (96\%) achieved complete or partial remission.

In 2 retrospective studies, the efficacy of TNFis was evaluated in a total of 33 neuro-BS patients who were resistant to other immunosuppressives. Two (6\%) patients relapsed under TNFis and 2 other relapsed after cessation of TNFis. ${ }^{46,47}$

First line use of biosimilar-infliximab was evaluated in a small retrospective study. Remission was achieved in 4 of 6 patients using first line biosimilar-infliximab. ${ }^{48}$ Switching from originator to biosimilar-infliximab was evaluated in 2 small retrospective studies. The first study reported 3 patients who failed after switching from originator to biosimilar-infliximab. ${ }^{49}$ In the second study, 13 patients were switched to biosimilar-infliximab after $106.92 \pm 46.37$ months of treatment with originatorinfliximab. $^{50}$ Only 2 patients stopped biosimilarinfliximab due to relapse of mucocutaneous involvement at month 6 .

Immunogenicity of infliximab in BS patients was evaluated in a controlled study. ${ }^{51}$ Serum samples from 66

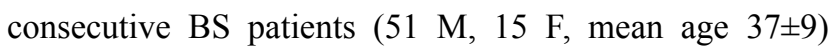
treated with infliximab were compared with similarly treated rheumatoid arthritis, ankylosing spondylitis and Crohn's disease patients. Anti-infliximab antibody levels in BS $(6 \%)$ were lower than rheumatoid arthritis $(19 \%)$ and Crohn's disease (12\%) but slightly higher than ankylosing spondylitis $(2 \%)$.

\section{IL-I Inhibitors}

Gevokizumab, an anti-IL-1 $\beta$ monoclonal antibody, demonstrated rapid and sustained inhibition of intraocular inflammation in an open-label proof of concept study ( $\mathrm{n}=7)$ and a Phase II non-controlled study $(\mathrm{n}=21) .{ }^{52,53}$ However, the Phase III placebo-controlled trial $(\mathrm{n}=83)$ was prematurely ended because the primary endpoint, the time to the next ocular attack, was not met (Table 1). ${ }^{54}$

Recently, a SR evaluated the efficacy of all IL-1 inhibitors in BS. ${ }^{55}$ All type of studies including case reports and letter to the editor were reviewed. The efficacy of anakinra was evaluated in 15 , canakinumab in 8 , and both drugs in 4 studies (218 patients). Some beneficial effects of IL-1 inhibitors on mucocutaneous, eye and joint involvement were observed. Authors suggested that IL-1 inhibitors can be an alternative therapeutic option in some clusters of BS involvement.

\section{Tocilizumab}

There are several small case series reporting the efficacy of tocilizumab in BS. ${ }^{56}$ Overall 47 patients who had been treated with tocilizumab were evaluated in a SR (Table 1). Tocilizumab was found effective in ocular, vascular and neurologic involvement and secondary amyloidosis. On the other hand, tocilizumab did not show the same efficacy in mucocutaneous, joint and gastrointestinal involvement. Moreover, exacerbation as a paradox reaction in mucocutaneous findings was reported with tocilizumab. ${ }^{57-59}$

\section{Secukinumab}

Secukinumab (300 mg every 2 weeks or every 4 weeks), was evaluated in a RCT for the treatment of BS uveitis 
$(\mathrm{n}=118)$ (Table 1). ${ }^{60}$ The primary endpoint, the reduction in ocular attack rate, was not achieved with either dose in the trial (MD 0.0, 95\% CI 9.9-9.9 for secukinumab $\mathrm{q} 2 \mathrm{w}$ and MD 3.80, 95\% CI 7.41-15.01 for secukinumab q4w). Secukinumab had to be stopped in two patients with ocular $\mathrm{AE}$ and five patients with non-ocular AE.

After demonstrating the efficacy of secukinumab in mucocutaneous and joint involvement in a small study $(n=5)$, long-term efficacy and safety data for 15 patients were published by the same group. ${ }^{61,62}$ They included patients who had active mucocutaneous and articular manifestations refractory to colchicine, conventional DMARDs and at least one TNFi. Response (complete or partial) was obtained in $87 \%$ of patients at month 6 and in all patients after 24 months. Candida infection was detected in two patients. On the other hand, there are some case reports reporting exacerbation of BS symptoms or emergence of de novo BS. ${ }^{63-65}$ Three patients with PsA and one with AS developed de novo BS. All patients developed mucocutaneous symptoms. In addition, 2 patients had uveitis and 1 had superficial thrombophlebitis. In another patient with a previously known diagnosis of $\mathrm{BS}$ and AS, a new gastrointestinal involvement in addition to exacerbation of mucocutaneous and joint findings developed under secukinumab. ${ }^{63}$

\section{Ustekinumab}

Ustekinumab is a monoclonal antibody targeting IL12/23. The efficacy of ustekinumab on OUs was evaluated in 2 studies (Table 1). The first study included 14 BS patients in whom OUs were resistant to colchicine. ${ }^{66}$ Patients were given ustekinumab $90 \mathrm{mg}$ at week 0,4 and then every 12 weeks. Sixty-four percent of the patients achieved CR which was defined as no OU at week 12. The same group also reported the long-term efficacy and safety of ustekinumab in a multicenter, prospective, open-label study in 30 BS patients. ${ }^{67}$ The inclusion criteria were the same as in the previous study. CR was achieved in $60 \%$ and $89 \%$ of patients at weeks 12 and 24, respectively. Four patients stopped ustekinumab due to AEs (headache) in 1 patient and BS activation (eye, vascular, mucocutaneous and joint symptoms) in 3 patients.

\section{Small Molecules}

\section{Apremilast}

A phosphodiesterase-4 inhibitor, (30 mg twice a day) was evaluated in two RCT $(n=111, n=207)$ designed to test response to OUs in patients with $\mathrm{BS}$ (Table 1). ${ }^{68,69}$ In both trials, all OU-related endpoints showed a significantly greater improvement with apremilast compared to placebo. In addition to these two trials, there are also published observational studies investigating the safety and efficacy of apremilast in BS patients. A significant reduction in the number of OUs and GUs was observed, and a dramatic improvement was achieved in QoL. In the other observational study $(n=51)$, clinical findings such as follicular lesions and intestinal symptoms in addition to OUs and GUs were evaluated and an improvement was reported. ${ }^{70}$ Efficacy of apremilast on joint involvement was also evaluated in another observational study. Among 30 patients who had refractory joint involvement, $65 \%$ had complete response and 17\% had partial response at month $6 .^{71}$ Apremilast was generally well tolerated, the main AEs being related to the gastrointestinal system.

\section{Tofacitinib}

A JAK inhibitor, (5 mg twice a day) was used in a small group $(n=7)$ to demonstrate the efficacy in refractory BS patients (Table 1). ${ }^{72}$ Clinical signs and laboratory parameters were followed for 12-24 weeks. Improvement in clinical symptoms in terms of vascular and joint involvement were reported, while gastrointestinal manifestations responded poorly. Two patients withdrew tofacitinib due to herpes zoster infection. Another study reported 13 BS patients with refractory uveitis. Rapid and sustained improvement in visual acuity and intraocular inflammation were obtained in $10(\% 77)$ patients. $^{73}$ Three patients had flares and one patient had herpes zoster infection.

\section{Surgical Approach and Interventions}

Peripheral artery aneurysms usually necessitate surgical intervention. Endovascular grafts, bypass surgery, ligation, and graft interposition are all potential procedures in these patients. Peripheral arterial ligation was reported in 4 retrospective studies. ${ }^{4}$ Among a total of 20 patients, relapses occurred in five and death in one. By-pass surgery was evaluated in a total of 32 patients in 5 retrospective studies. Relapses occurred in 11 (34\%), occlusion in 5 $(16 \%)$ and death in $6(14 \%)$ patients. Graft interposition was reported in overall 48 patients. Fourteen (29\%) patients experienced graft occlusion, 13 (27\%) relapsed and 7 (15\%) died. 
Pulmonary hemorrhage due to PA aneurysm (PAA) is one of the most mortal complications of BS and requires urgent intervention. In retrospective series, death was reported in $6(75 \%)$ of 8 patients after open surgery and in $4(57 \%)$ of 7 patients after PA embolization. ${ }^{4}$ Open surgical procedures had higher mortality rates in earlier cohorts. In a recent study published from our center mortality rate was lower in 9 patients who underwent open surgery. ${ }^{74}$ Lobectomy was performed in 6 patients due to a giant aneurysm. Decortications and pleural procedures were performed in one patient each due to a bronchopleural fistula following PA coil embolization and pneumothorax due to large cavities. Two (22\%) patients died after lobectomy. One died 3 months after surgery due to massive hemoptysis and the other died 12 months after surgery due to Budd-Chiari syndrome.

Refractory hemoptysis due to bronchial artery enlargement can be seen in patients with PA involvement. In a retrospective study, bronchial artery embolization was performed in 6 patients. $^{75}$ One patient died after 3 weeks of the procedure due to severe pulmonary hypertension. Pulmonary infarction and hemiparesis were observed in one patient each. The remaining 5 were under follow-up for 5 months to 9 years.

Endarterectomy was performed in 9 BS patients with chronic thromboembolic hypertension. Endarterectomy provided a symptomatic improvement in eight patients during a median follow-up of 24 months and resulted in death in 1 patient one month after surgery. ${ }^{76}$ Since immunosuppressive therapy is the main treatment modality in venous involvement in BS, invasive procedures are generally not needed. Forty-one vascular BS patients who had invasive procedures were evaluated in a case series and SR. Overall $22(54 \%)$ had an unfavorable outcome. Ileal infarct and vena cava wall-duodenal perforation were detected as major complications. ${ }^{77}$

\section{Management According to Clinical Manifestations}

Management of BS is planned according to the organs and systems that are involved, severity of involvement and disease activity. ${ }^{3}$ The traditional first-line agent for the management of skin, mucosa and joint involvement has been colchicine. However, as explained above, its efficacy may be limited for OUs and apremilast may be preferred in patients with recurrent OUs and GUs. Azathioprine, interferon-alpha and TNFis have been used in refractory patients. Ustekinumab, secukinumab, IL-1 inhibitors and tofacitinib have been tried with some success for these manifestations. ${ }^{55,61,62,66,67,72}$

For patients with active posterior or panuveitis it is imperative to use immunosuppressive or biologic agents together with corticosteroids. ${ }^{3}$ Commonly used immunosuppressive agents are azathioprine, cyclosporine-A and mycophenolate. ${ }^{3}$ Biologic agents including interferonalpha and TNFis may be used first-line in sight threatening cases or in patients with refractory uveitis. ${ }^{3}$ Experience with beneficial use of IL-1 and IL-6 inhibitors have also been reported. ${ }^{55,56}$

Arterial aneurysms, the most feared complication of BS is treated with high dose corticosteroids, typically 3 pulses of $1 \mathrm{gr}$ intravenous methylprednisolone followed by prednisolone $1 \mathrm{mg} / \mathrm{kg}$ which is tapered over 6 months, together with cyclophosphamide or $\mathrm{TNFi}^{3}$ Potential short and long-term AEs with cyclophosphamide has led to increased use of TNFi, which also seem to be effective. Surgical or endovascular interventions may be required for peripheral artery and aortic aneurysms and it is important to perform these together with effective immunosuppression to prevent complications. ${ }^{3}$

Venous thrombosis in BS is immune mediated and thus requires treatment with immunosuppressives. ${ }^{3}$ Azathioprine may be preferred as first-line treatment, but recanalization of the thrombus may not always be possible and recurrences may be seen. Interferon-alpha and TNFi seem to be more effective and may be preferred in recurrent patients. ${ }^{14}$ Use of anticoagulants is not universally accepted, based on failure of preventing recurrences in retrospective studies and risk of fatal bleeding in case of concomitant arterial aneurysms. ${ }^{4}$ More serious venous involvement including vena cava superior and inferior thrombosis, hepatic vein thrombosis and intracardiac thrombosis need to be treated with cyclophosphamide or TNFi, similar to arterial involvement. ${ }^{3}$ Cerebral venous sinus thrombosis (CVST) should be treated with highdose glucocorticoids. Since the relapse of CVST is not frequent, first line use of immunosuppressives are not recommended. ${ }^{3}$ Also adding anticoagulants is controversial due to the risk of accompanying PAA. After screening for PAA, a short-term anticoagulant (3 to 6 months) can be added. If there is persistent papilledema despite this treatment, lumboperitoneal shunt may be considered. Leg ulcers (LUs) in BS may be associated with deep vein thrombosis, vasculitis, and pyoderma gangrenosum. ${ }^{78}$ 
LUs usually have a chronic recurrent course and are refractory to treatment. Treatment of BS-related venous LU in the absence of an inflammatory component consists of compression therapy and wound care as in venous LU associated with conditions other than BS. Vasculitis and pyoderma gangrenosum-like LU in BS usually require immunosuppressives.

The risk of permanent physical and cognitive disability due to nervous system involvement mandates aggressive treatment with high dose corticosteroids and immunosuppressives. ${ }^{3}$ Azathioprine, MMF and TNFi are the most commonly used agents. Tocilizumab was reported to provide benefit in a number of refractory patients with parenchymal nervous system involvement. ${ }^{56}$

Azathioprine may be used in patients with intestinal ulcers, and monoclonal TNFi may be added in refractory or severe cases. $^{12}$ Thalidomide have also shown benefit. ${ }^{31}$ Treatment with 5-ASA derivatives may be sufficient for patients with mild ulcers. ${ }^{12,79}$ Interestingly, myelodysplastic syndrome (MDS) was observed in some refractory cases of gastrointestinal involvement. Treatment of MDS seems to provide more benefit than immunosuppressives in such cases. ${ }^{80,81}$

\section{Treat to Target Approach and Disease Monitoring}

Treat to target approach, where patients are treated with the aim of obtaining a pre-defined target and monitored with standard assessment modalities within standard time intervals has been popular in rheumatology since it is suggested that this approach provides better long-term outcomes. This surely is a desirable goal for BS, too. However, an established treat to target strategy is not yet available for BS. It is obvious that a single strategy would not be applicable to all patients due to the heterogeneity of clinical phenotype in BS.

In patients who have only mucocutaneous lesions, the treatment goal is sustaining an optimum QoL. CR of mucocutaneous lesions may not be possible in a good proportion of patients, even with biologic agents. ${ }^{32,35}$ A minimum acceptable disease activity state needs to be identified in order to avoid excessive risk caused by treatment, when trying to obtain CR. The same is true for joint involvement since arthritis in BS typically follows a recurrent course without erosions or damage. On the other hand, for organ involvement $\mathrm{CR}$ and prevention of recurrences should be aimed in order to prevent damage and permanent loss of function. Disease assessment during follow-up comprises clinical and routine laboratory evaluation, as well as modalities such as fluorescein angiography for eye involvement, imaging with CT or MR angiography, or venous Doppler ultrasonography for vascular involvement, cranial MRI for nervous system involvement and colonoscopy for gastrointestinal involvement. Prediction of relapses and determining patients who require aggressive treatment is more challenging. The presence of capillary leakage on fluorescein angiography is thought to predict a worse outcome for uveitis, and is commonly utilized to guide treatment decisions. Lack of leakage is considered mandatory before tapering immunosuppressives. For venous involvement, lack of recanalization of thrombosis on Doppler ultrasonography was shown to be the best predictor of relapses. ${ }^{14}$ Intestinal ulcers may be asymptomatic until they reach a considerable size and depth. Colonoscopy used to be the modality of choice for monitoring patients with gastrointestinal involvement. A recent study showed that fecal calprotectin levels have good sensitivity to predict active gastrointestinal ulcers. Relapses are less frequent with nervous system involvement in BS, compared to other manifestations. Close follow-up for neurologic symptoms and cognitive function is the key since there are no diagnostic modalities for predicting a relapse of nervous system involvement.

Another component of defining a treat to target approach is determining the optimal frequency of assessment. Although an evidence-based strategy is not available, patients with active organ involvement are usually seen every 1-3 months until remission is obtained. For arterial and nervous system involvement this may even be as frequent as every 2 weeks, in order to ensure rapid suppression of inflammation and avoid damage accrual. Patients who have obtained remission are followed every 3-4 months for possible recurrences. For patients with only mucocutaneous and joint involvement follow-up frequency is usually 3-6 months during the early years of BS. This is not only for monitoring the course of mucocutaneous involvement but also for early recognition of any organ involvement. The frequency of follow-up visits may be reduced over the years, as the risk of severe disease decreases with age.

\section{Unmet Needs}

As summarized in this review, majority of the data on the treatment of major organ involvement is based on observational and retrospective studies. One of the reasons for scarcity of RCTs may be the need for standardized and 
validated outcome measures in BS. The recently published Core Set of domains endorsed by OMERACT is an important step, but there is still a lot to be done for developing a Core Set of outcome measures for BS. ${ }^{82}$ Controlled trials and especially head-to-head trials assessing the efficacy of biologic agents including TNFi, interferon-alpha, IL-1 and IL-6 inhibitors, a controlled study of anticoagulants for venous involvement, and studies comparing different management strategies including step-up or step-down treatment are needed. International collaboration is important for accomplishing these and providing optimal care for BS patients, which is a relatively rare condition in many parts of the world.

\section{Disclosure}

Dr Yesim Ozguler reports Speaker fee from UCB, and Pfizer, outside the submitted work;

Prof. Dr. Gulen Hatemi reports research grant, lecture fees and fees for serving on an advisory board from Celgene, receiving consulting fees from UCB Pharma, Bayer, Johnson \& Johnson, lecture fees from Novartis, Abbvie, Amgen, and UCB Pharma, grants from Silk Road Therapeutics outside the submitted work. The authors report no other conflicts of interest in this work.

\section{References}

1. Yazici H, Seyahi E, Hatemi G, Yazici Y. Behcet syndrome: a contemporary view. Nat Rev Rheumatol. 2018;14(2):119. doi:10.1038/nrrheum.2018.3

2. Mendoza-Pinto C, Garcia-Carrasco M, Jimenez-Hernandez M, et al. Etiopathogenesis of Behcet's disease. Autoimmun Rev. 2010;9 (4):241-245. doi:10.1016/j.autrev.2009.10.005

3. Hatemi G, Christensen R, Bang D, et al. 2018 update of the EULAR recommendations for the management of Behcet's syndrome. Ann Rheum Dis. 2018;77(6):808-818. doi:10.1136/annrheumdis-2018-213225

4. Ozguler Y, Leccese P, Christensen R, et al. Management of major organ involvement of Behcet's syndrome: a systematic review for update of the EULAR recommendations. Rheumatology (Oxford). 2018;57(12):2200-2212. doi:10.1093/rheumatology/key242

5. Leccese P, Ozguler Y, Christensen R, et al. Management of skin, mucosa and joint involvement of Behcet's syndrome: a systematic review for update of the EULAR recommendations for the management of Behcet's syndrome. Semin Arthritis Rheum. 2019;48 (4):752-762. doi:10.1016/j.semarthrit.2018.05.008

6. Aktulga E, Altac M, Muftuoglu A, et al. A double blind study of colchicine in Behcet's disease. Haematologica. 1980;65(3):399-402.

7. Yurdakul S, Mat C, Tuzun Y, et al. A double-blind trial of colchicine in Behcet's syndrome. Arthritis Rheum. 2001;44(11):2686-2692. doi:10.1002/1529-0131(200111)44:11<2686::AID-ART448>3.0. $\mathrm{CO} ; 2-\mathrm{H}$

8. Davatchi F, Sadeghi Abdollahi B, Tehrani Banihashemi A, et al. Colchicine versus placebo in Behcet's disease: randomized, doubleblind, controlled crossover trial. Mod Rheumatol. 2009;19(5):542-549. doi:10.3109/s10165-009-0200-2
9. Hamuryudan V, Hatemi G, Tascilar K, et al. Colchicine in Behcet syndrome: a long term survey of patients in a controlled trial. $J$ Rheumatol. 2014;41(4):735-738. doi:10.3899/jrheum.130847

10. Yazici H, Pazarli H, Barnes CG, et al. A controlled trial of azathioprine in Behcet's syndrome. $N$ Engl J Med. 1990;322(5):281-285. doi:10.1056/NEJM199002013220501

11. Hamuryudan V, Ozyazgan Y, Hizli N, et al. Azathioprine in Behcet's syndrome: effects on long-term prognosis. Arthritis Rheum. 1997;40 (4):769-774. doi:10.1002/art.1780400425

12. Hatemi I, Esatoglu SN, Hatemi G, Erzin Y, Yazici H, Celik AF. Characteristics, treatment, and long-term outcome of gastrointestinal involvement in behcet's syndrome: a strobe-compliant observational study from a dedicated multidisciplinary center. Medicine (Baltimore). 2016;95(16):e3348. doi:10.1097/MD.0000000000003348

13. Jung YS, Cheon JH, Hong SP, Kim TI, Kim WH. Clinical outcomes and prognostic factors for thiopurine maintenance therapy in patients with intestinal Behcet's disease. Inflamm Bowel Dis. 2012;18 (4):750-757. doi:10.1002/ibd.21757

14. Ozguler Y, Hatemi G, Cetinkaya F, et al. Clinical course of acute deep vein thrombosis of the legs in Behcet's syndrome. Rheumatology (Oxford). 2020;59(4):799-806.

15. Girgin S, Yurumez S, Omma A, et al. Comparison of relapse rates in Behcet's disease with venous involvement on different doses of azathioprine therapy, a retrospective observational study. Int J Rheum Dis. 2021;24:562-566. doi:10.1111/1756-185X.14075

16. Noel N, Bernard R, Wechsler B, et al. Long-term outcome of neuroBehcet's disease. Arthritis Rheumatol. 2014;66(5):1306-1314. doi:10.1002/art.38351

17. Hamuryudan V, Ozyazgan Y, Fresko Y, Mat C, Yurdakul S, Yazici $\mathrm{H}$. Interferon alfa combined with azathioprine for the uveitis of Behcet's disease: an open study. Isr Med Assoc J. 2002;4(11 Suppl):928-930.

18. BenEzra D, Cohen E, Chajek T, et al. Evaluation of conventional therapy versus cyclosporine A in Behcet's syndrome. Transplant Proc. 1988;20(3 Suppl 4):136-143.

19. Ozyazgan Y, Yurdakul S, Yazici H, et al. Low dose cyclosporin A versus pulsed cyclophosphamide in Behcet's syndrome: a single masked trial. Br J Ophthalmol. 1992;76(4):241-243. doi:10.1136/bjo.76.4.241

20. Masuda K, Nakajima A, Urayama A, Nakae K, Kogure M, Inaba G. Double-masked trial of cyclosporin versus colchicine and long-term open study of cyclosporin in Behcet's disease. Lancet. 1989;1 (8647):1093-1096. doi:10.1016/S0140-6736(89)92381-7

21. Celiker H, Kazokoglu H, Direskeneli H. Conventional immunosuppressive therapy in severe Behcet's Uveitis: the switch rate to the biological agents. BMC Ophthalmol. 2018;18(1):261. doi:10.1186/ s12886-018-0929-5

22. Adler YD, Mansmann U, Zouboulis CC. Mycophenolate mofetil is ineffective in the treatment of mucocutaneous Adamantiades-Behcet's disease. Dermatology. 2001;203(4):322-324. doi:10.1159/000051781

23. Kose O, Simsek I, Pay S. Mycophenolate sodium in the treatment of mucocutaneous Behcet's diseases. Int $J$ Dermatol. 2011;50 (7):895-896. doi:10.1111/j.1365-4632.2010.04505.x

24. Esatoglu SN, Cemre E, Hamuryudan V, et al. Mycophenolate mofetil in the treatment of major organ involvement of patients with behçet's syndrome. Eur Congress Rheumatol. 2019;12-15(June):2019.

25. Shugaiv E, Tuzun E, Mutlu M, Kiyat-Atamer A, Kurtuncu M, Akman-Demir G. Mycophenolate mofetil as a novel immunosuppressant in the treatment of neuro-Behcet's disease with parenchymal involvement: presentation of four cases. Clin Exp Rheumatol. 2011;29(4 Suppl 67):S64-67.

26. Hamuryudan V, Yurdakul S, Moral F, et al. Pulmonary arterial aneurysms in Behcet's syndrome: a report of 24 cases. $\mathrm{Br} J$ Rheumatol. 1994;33(1):48-51. doi:10.1093/rheumatology/33.1.48

27. Saba D, Saricaoglu H, Bayram AS, et al. Arterial lesions in Behcet's disease. Vasa. 2003;32(2):75-81. doi:10.1024/0301-1526.32.2.75 
28. Yoon DL, Kim YJ, Koo BS, Kim YG, Lee CK, Yoo B. Neurobehcet's disease in South Korea: clinical characteristics and treatment response. Int $J$ Rheum Dis. 2014;17(4):453-458. doi:10.1111/1756$185 X .12265$

29. Gurcan M, Esatoglu SN, Hamuryudan V, et al. Long term follow-up of Behcet's syndrome patients treated with cyclophosphamide. Rheumatology (Oxford). 2020;59(9):2264-2271. doi:10.1093/rheumatology/kez598

30. Hamuryudan V, Mat C, Saip S, et al. Thalidomide in the treatment of the mucocutaneous lesions of the Behcet syndrome. A randomized, double-blind, placebo-controlled trial. Ann Intern Med. 1998;128 (6):443-450. doi:10.7326/0003-4819-128-6-199803150-00004

31. Hatemi I, Hatemi G, Pamuk ON, Erzin Y, Celik AF. TNF-alpha antagonists and thalidomide for the management of gastrointestinal Behcet's syndrome refractory to the conventional treatment modalities: a case series and review of the literature. Clin Exp Rheumatol. 2015;33(6 Suppl 94):S129-137.

32. Alpsoy E, Durusoy C, Yilmaz E, et al. Interferon alfa-2a in the treatment of Behcet disease: a randomized placebo-controlled and double-blind study. Arch Dermatol. 2002;138(4):467-471. doi:10.10 01/archderm.138.4.467

33. Kötter I, Vonthein R, Schoenfisch B, et al. Interferon alpha2a versus cyclosporin a for the treatment of severe ocular behcet's disease a prospective, randomised, single blind, national multicenter trial (INCYTOB). Annual Eur Congress Rheumatol. 2016. London, United Kingdom.

34. Lightman S, Taylor SR, Bunce C, et al. Pegylated interferon-alpha-2b reduces corticosteroid requirement in patients with Behcet's disease with upregulation of circulating regulatory $\mathrm{T}$ cells and reduction of Th17. Ann Rheum Dis. 2015;74(6):1138-1144. doi:10.1136/ annrheumdis-2014-205571

35. Melikoglu M, Fresko I, Mat C, et al. Short-term trial of etanercept in Behcet's disease: a double blind, placebo controlled study. J Rheumatol. 2005;32(1):98-105.

36. Jaffe GJ, Dick AD, Brezin AP, et al. Adalimumab in patients with active noninfectious uveitis. $N$ Engl J Med. 2016;375(10):932-943. doi:10.1056/NEJMoa1509852

37. Nguyen QD, Merrill PT, Jaffe GJ, et al. Adalimumab for prevention of uveitic flare in patients with inactive non-infectious uveitis controlled by corticosteroids (VISUAL II): a multicentre, double-masked, randomised, placebo-controlled Phase 3 trial. Lancet. 2016;388 (10050):1183-1192. doi:10.1016/S0140-6736(16)31339-3

38. Hu Y, Huang Z, Yang S, Chen X, Su W, Liang D. Effectiveness and safety of anti-tumor necrosis factor-alpha agents treatment in behcets' disease-associated uveitis: a systematic review and meta-analysis. Front Pharmacol. 2020;11:941. doi:10.3389/fphar.2020.00941

39. Atienza-Mateo B, Martin-Varillas JL, Calvo-Rio V, et al. Comparative study of infliximab versus adalimumab in refractory uveitis due to behcet's disease: national multicenter study of 177 cases. Arthritis Rheumatol. 2019;71(12):2081-2089. doi:10.1002/art.41026

40. Fabiani C, Vitale A, Rigante D, et al. Comparative efficacy between adalimumab and infliximab in the treatment of non-infectious intermediate uveitis, posterior uveitis, and panuveitis: a retrospective observational study of 107 patients. Clin Rheumatol. 2019;38 (2):407-415. doi:10.1007/s10067-018-4228-6

41. Suzuki Y, Hagiwara T, Kobayashi M, Morita K, Shimamoto T, Hibi T. Long-term safety and effectiveness of adalimumab in 462 patients with intestinal Behcet's disease: results from a large realworld observational study. Intest Res. 2020.

42. Lopalco G, Emmi G, Gentileschi S, et al. Certolizumab Pegol treatment in Behcet's disease with different organ involvement: a multicenter retrospective observational study. Mod Rheumatol. 2017;27(6):1031-1035. doi:10.1080/14397595.2017.1285857

43. Vitale A, Emmi G, Lopalco G, et al. Long-term efficacy and safety of golimumab in the treatment of multirefractory Behcet's disease. Clin Rheumatol. 2017;36(9):2063-2069. doi:10.1007/s10067-017-3627-4
44. Aksoy A, Yazici A, Omma A, et al. Efficacy of TNFalpha inhibitors for refractory vascular Behcet's disease: a multicenter observational study of 27 patients and a review of the literature. Int J Rheum Dis. 2020;23(2):256-261. doi:10.1111/1756-185X.13778

45. Li L, Liu JJ, Yu X, et al. [Efficacy and safety of anti-tumor necrosis factor alpha monoclonal antibodies in 16 patients with severe/refractory vasculo Behcet's disease]. Zhonghua Nei Ke Za Zhi. 2020;59(4):303-308. Chinese. doi:10.3760/cma.j.cn11213820190730-00527

46. Desbois AC, Addimanda O, Bertrand A, et al. Efficacy of anti-tnfalpha in severe and refractory neuro-behcet disease: an observational study. Medicine (Baltimore). 2016;95(23):e3550. doi:10. 1097/MD.0000000000003550

47. Zeydan B, Uygunoglu U, Saip S, et al. Infliximab is a plausible alternative for neurologic complications of Behcet disease. Neurol Neuroimmunol Neuroinflamm. 2016;3(5):e258. doi:10.1212/NXI.00 00000000000258

48. Dincses E, Esatoglu SN, Ozguler Y, et al. Biosimilar infliximab for Behcet's syndrome: a case series. Clin Exp Rheumatol. 2019;37 Suppl 121(6):111-115.

49. Cantini F, Niccoli L, Nannini C, Cassara E, Kaloudi O. Rapid loss of efficacy of biosimilar infliximab in three patients with Behcet's disease after switching from infliximab originator. Eur $J$ Rheumatol. 2017;4(4):288-290. doi:10.5152/eurjrheum.2017.16112

50. Lopalco G, Venerito V, Cantarini L, Emmi G, Prisco D, Iannone F. Long-term effectiveness and safety of switching from originator to biosimilar infliximab in patients with Behcet's disease. Intern Emerg Med. 2019;14(5):719-722. doi:10.1007/s11739-018-1970-3

51. Esatoglu SN, Akkoc-Mustafayev FN, Ozguler Y, et al. Immunogenicity of infliximab among patients with behcet syndrome: a controlled study. Front Immunol. 2020;11:618973. doi:10.3389/ fimmu.2020.618973

52. Gul A, Tugal-Tutkun I, Dinarello CA, et al. Interleukin-1betaregulating antibody XOMA 052 (gevokizumab) in the treatment of acute exacerbations of resistant uveitis of Behcet's disease: an openlabel pilot study. Ann Rheum Dis. 2012;71(4):563-566. doi:10.1136/ annrheumdis-2011-155143

53. Tugal-Tutkun IM, Kadayifcilar SM, Khairallah MM, et al. Safety and efficacy of gevokizumab in patients with behcet's disease uveitis: results of an exploratory phase 2 study. Ocul Immunol Inflamm. 2017;25(1):62-70. doi:10.3109/09273948.2015.1092558

54. Tugal-Tutkun I, Pavesio C, De Cordoue A, Bernard-Poenaru O, Gul A. Use of gevokizumab in patients with behcet's disease uveitis: an international, randomized, double-masked, placebo-controlled study and open-label extension study. Ocul Immunol Inflamm. 2018;26(7):1023-1033. doi:10.1080/09273948.2017.1421233

55. Bettiol A, Silvestri E, Di Scala G, et al. The right place of interleukin-1 inhibitors in the treatment of Behcet's syndrome: a systematic review. Rheumatol Int. 2019;39(6):971-990. doi:10. 1007/s00296-019-04259-y

56. Akiyama M, Kaneko Y, Takeuchi T. Effectiveness of tocilizumab in Behcet's disease: a systematic literature review. Semin Arthritis Rheum. 2020;50(4):797-804. doi:10.1016/j.semarthrit.2020.05.017

57. Emmi G, Silvestri E, Squatrito D, Emmi L, Cantarini L, Prisco D. Tocilizumab-induced exacerbation of mucosal ulcers in a patient with multi-refractory Behcets disease. Semin Arthritis Rheum. 2016;46(1): e1-2. doi:10.1016/j.semarthrit.2016.03.006

58. Cantarini L, Lopalco G, Vitale A, et al. Paradoxical mucocutaneous flare in a case of Behcet's disease treated with tocilizumab. Clin Rheumatol. 2015;34(6):1141-1143. doi:10.1007/s10067-014$2589-\mathrm{z}$

59. Diamantopoulos AP, Hatemi G. Lack of efficacy of tocilizumab in mucocutaneous Behcet's syndrome: report of two cases. Rheumatology (Oxford). 2013;52(10):1923-1924. doi:10.1093/rheumatology/ket130 
60. Dick AD, Tugal-Tutkun I, Foster S, et al. Secukinumab in the treatment of noninfectious uveitis: results of three randomized, controlled clinical trials. Ophthalmology. 2013;120(4):777-787. doi:10.1016/j. ophtha.2012.09.040

61. Di Scala G, Bettiol A, Cojan RD, Finocchi M, Silvestri E, Emmi G. Efficacy of the anti-IL 17 secukinumab in refractory Behcet's syndrome: a preliminary study. J Autoimmun. 2019;97:108-113. doi:10.1016/j.jaut.2018.09.002

62. Fagni F, Bettiol A, Talarico R, et al. Long-term effectiveness and safety of secukinumab for treatment of refractory mucosal and articular Behcet's phenotype: a multicentre study. Ann Rheum Dis. 2020;79 (8):1098-1104. doi:10.1136/annrheumdis-2020-217108

63. Dincses E, Yurttas B, Esatoglu SN, Melikoglu M, Hamuryudan V, Seyahi E. Secukinumab induced Behcet's syndrome: a report of two cases. Oxf Med Case Rep. 2019;2019(5):omz041. doi:10.1093/omcr/ omz041

64. Calleja Algarra A, Aragon Miguel R, Andres Lencina JJ, et al. Behcet's-like disease during secukinumab treatment: new paradoxical reaction? J Dtsch Dermatol Ges. 2021;19(1):116-118.

65. Barrado-Solis N, Rodrigo-Nicolas B, De la Morena-barrio I, et al. Report of two cases of Behcet's disease developed during treatment with secukinumab. J Eur Acad Dermatol Venereol. 2020;34(10): e587-e589. doi:10.1111/jdv.16454

66. Mirouse A, Barete S, Monfort JB, et al. Ustekinumab for Behcet's disease. J Autoimmun. 2017;82:41-46. doi:10.1016/j.jaut.2017.05.002

67. Mirouse A, Barete S, Desbois AC, et al. Long-term outcome of ustekinumab therapy for behcet's disease. Arthritis Rheumatol. 2019;71(10):1727-1732. doi:10.1002/art.40912

68. Hatemi G, Melikoglu M, Tunc R, et al. Apremilast for Behcet's syndrome-a phase 2, placebo-controlled study. $N$ Engl J Med. 2015;372(16):1510-1518. doi:10.1056/NEJMoa1408684

69. Hatemi G, Mahr A, Ishigatsubo Y, et al. Trial of apremilast for oral ulcers in behcet's syndrome. $N$ Engl $J$ Med. 2019;381 (20):1918-1928. doi:10.1056/NEJMoa1816594

70. Atienza-Mateo B, Martin-Varillas JL, Grana J, et al. Apremilast in refractory orogenital ulcers and other manifestations of Behcet's disease. A national multicentre study of 51 cases in clinical practice. Clin Exp Rheumatol. 2020;38 Suppl 127(5):69-75.

71. Vieira M, Buffier S, Vautier M, et al. Apremilast in refractory behcet's syndrome: a multicenter observational study. Front Immunol. 2020;11:626792. doi:10.3389/fimmu.2020.626792
72. Liu J, Hou Y, Sun L, et al. A pilot study of tofacitinib for refractory Behcet's syndrome. Ann Rheum Dis. 2020;79(11):1517-1520. doi:10.1136/annrheumdis-2020-217307

73. Liu J, Zhao C, Zheng W. Response to: 'Correspondence on 'A pilot study of tofacitinib for refractory Behcet's syndrome" by Zou et al. Ann Rheum Dis. 2021. doi:10.1136/annrheumdis-2020-219828

74. Tuzun H, Seyahi E, Guzelant G, et al. Surgical treatment of pulmonary complications in behcet's syndrome. Semin Thorac Cardiovasc Surg. 2018;30(3):369-378. doi:10.1053/j.semtcvs.2018.07.008

75. Esatoglu SN, Seyahi E, Ugurlu S, et al. Bronchial artery enlargement may be the cause of recurrent haemoptysis in Behcet's syndrome patients with pulmonary artery involvement during follow-up. Clin Exp Rheumatol. 2016;34(6 Suppl 102):92-96.

76. Yildizeli SO, Yanartas M, Tas S, et al. Outcomes of patients with behcet's syndrome after pulmonary endarterectomy. Thorac Cardiovasc Surg. 2018;66(2):187-192. doi:10.1055/s-0037-1604411

77. Dincses E, Esatoglu SN, Fresko I, Melikoglu M, Seyahi E. Outcome of invasive procedures for venous thrombosis in Behcet's syndrome: case series and systematic literature review. Clin Exp Rheumatol. 2019;37 Suppl 121(6):125-131.

78. Jung JY, Kim DY, Bang D. Leg ulcers in Behcet's disease. $B r$ $J$ Dermatol. 2008;158(1):178-179. doi:10.1111/j.1365-2133.2007. 08234.x

79. Jung YS, Hong SP, Kim TI, Kim WH, Cheon JH. Long-term clinical outcomes and factors predictive of relapse after 5-aminosalicylate or sulfasalazine therapy in patients with intestinal Behcet disease. $J$ Clin Gastroenterol. 2012;46(5):e38-45. doi:10.1097/MCG.0b013e318243 $1 \mathrm{~d} 56$

80. Soysal T, Salihoglu A, Esatoglu SN, et al. Bone marrow transplantation for Behcet's disease: a case report and systematic review of the literature. Rheumatology (Oxford). 2014;53(6):1136-1141. doi:10.10 93/rheumatology/ket479

81. Yilmaz U, Ar MC, Esatoglu SN, et al. How to treat myelodysplastic syndrome with clinical features resembling Behcet syndrome: a case-based systematic review. Ann Hematol. 2020;99(6):1193-1203. doi:10.1007/s00277-020-03951-5

82. Hatemi G, Meara A, Ozguler Y, et al. The OMERACT core set of domains for outcome measures in behcet syndrome. Arthritis Care Res (Hoboken). 2020. doi:10.1002/acr.24511
Journal of Inflammation Research

\section{Publish your work in this journal}

The Journal of Inflammation Research is an international, peerreviewed open-access journal that welcomes laboratory and clinica findings on the molecular basis, cell biology and pharmacology of inflammation including original research, reviews, symposium reports, hypothesis formation and commentaries on: acute/chronic inflammation; mediators of inflammation; cellular processes; molecula mechanisms; pharmacology and novel anti-inflammatory drugs; clinical conditions involving inflammation. The manuscript management system is completely online and includes a very quick and fair peerreview system. Visit http://www.dovepress.com/testimonials.php to read real quotes from published authors. 